\title{
Determination of Risk Factors in Children Diagnosed With Henoch-Scho̊nlein Purpura
}

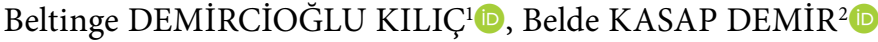 \\ ${ }^{1}$ Department of Child Health and Diseases, Division of Pediatric Nephrology, Medicine Faculty of Gaziantep University, Gaziantep, Turkey \\ ${ }^{2}$ Department of Pediatric Nephrology and Rheumatology, Katip Çelebi University, İzmir, Turkey
}

\begin{abstract}
Objectives: This study aims to evaluate the frequency of skin, gastrointestinal, joint, and renal involvement in children with Henoch-Schönlein purpura (HSP) and investigate the risk factors for organ/system involvement.

Patients and methods: The data of 186 patients ( 97 boys, 89 girls; mean age $7.4 \pm 2.8$ years; range 1.5 to 16.5 years) who were followed-up with the diagnosis of HSP in our clinic between October 2011 and December 2013 were evaluated retrospectively.

Results: Logistic regression analysis revealed that the risk of gastrointestinal system (GIS) involvement was significantly higher in patients with skin lesions in the upper extremities $(p=0.002$, odds ratio $[O R]=3.2)$. The risk of joint involvement was significantly higher in girls $(p=0.024,0 R=2.18)$, in patients with soft tissue swelling $(p=0.005, O R=2.63)$, and with low mean platelet volume $(M P V)$ levels ( $p=0.008, O R=4.07)$. The risk of renal involvement was significantly higher in girls $(p=0.047, O R=2.7)$, in patients $>10$ years $(p=0.001, O R=1.4)$, and in patients with elevated $C$-reactive protein (CRP) levels $(p=0.007, O R=6.57)$.

Conclusion: Having skin lesions in the upper extremities is a risk factor for GIS involvement. Female sex, soft tissue swelling, and low MPV levels are risk factors for joint involvement. Female sex, $>10$ years of age, and high CRP levels are risk factors for renal involvement. Renal involvement in HSP is independent of GIS or joint involvement and very close follow-up is required in the acute period particularly in girls $>10$ years with high CRP levels. Keywords: Children; Henoch-Schönlein purpura; organ/system involvement; risk factors.
\end{abstract}

Henoch-Schönlein purpura (HSP) is the most common vasculitis in children characterized by non-thrombocytopenic purpura, arthritis or arthralgia, gastrointestinal system (GIS), and renal involvement caused by systemic leukocytoclastic angiitis and deposition of immunoglobulin $\mathrm{A}(\mathrm{Ig} \mathrm{A})$ containing immune complexes and complement components mainly affecting the small vessels. Central nervous system, lungs and male genital system involvement including epididymo-orchitis, testicular torsion or acute scrotal edema may also be occasionally observed. ${ }^{1}$

Henoch-Schönlein purpura is usually a self-limiting disease, but rarely with life-threatening complications, while intussusception and intestinal perforation may be seen..$^{2,3}$ Long-term prognosis is associated with renal involvement. However, the incidence depends on the definition of renal involvement. Some HSP patients may only have microscopic hematuria, while others progress to permanent renal damage. ${ }^{1}$ Most HSP patients with renal involvement have a considerably good prognosis. $^{4}$

Although HSP is mostly a benign process, early prediction of the risk factors for organ and system involvement may prevent complications. Therefore, in this study, we aimed to evaluate the frequency of skin, gastrointestinal, joint, and renal involvement in children with HSP and investigate the risk factors for organ/system involvement.

Received: July 04, 2017 Accepted: December 28, 2017 Published online: January 30, 2018

Correspondence: Beltinge Demircioğlu Kılıç, MD. Gaziantep Üniversitesi Tıp Fakültesi Çocuk Sağlığı ve Hastalıkları Anabilim Dalı, Çocuk Nefrolojisi Bilim Dalı, 27310 Şehitkamil, Gaziantep, Turkey. Tel: +90342 - 3606060 e-mail: beltingeiklim@hotmail.com 


\section{PATIENTS AND METHODS}

The data of 186 patients (97 boys, 89 girls; mean age $7.4 \pm 2.8$ years; range 1.5 to 16.5 years) diagnosed with HSP and followed-up for at least six months in the Pediatric Nephrology Clinic of Gaziantep Children's Hospital between October 2011 and December 2013 were evaluated retrospectively. The mean follow-up period was $16.9 \pm 8.2$ months (range 6 to 34 months). Diagnostic criteria of the European League Against Rheumatism/the Paediatric Rheumatology European Society/ Pediatric Rheumatology International Trials Organization (EULAR/PRES/PRINTO) were used to define HSP. ${ }^{5}$ Palpable purpura was the mandatory criterion and the existence of at least one of the following was accepted sufficient for the diagnosis: diffuse abdominal pain, any biopsy showing predominant IgA deposition, arthritis or arthralgia, and renal involvement (hematuria and/or proteinuria). The study was conducted in accordance with the principles of the Declaration of Helsinki.

The age and sex of the patients, clinical findings and follow-up, mean platelet volume (MPV), C-reactive protein (CRP), anti-streptolysin O (ASO), $\mathrm{IgA}, \mathrm{C} 3$, and $\mathrm{C} 4$ levels were recorded from patient files, retrospectively. The laboratory findings were recorded on the first visit without any treatment. Patients $>10$ years were determined as older patients. IgA $>400 \mathrm{mg} / \mathrm{dL}, \mathrm{CRP}>0.5 \mathrm{mg} / \mathrm{dL}$, ASO > 200IU/mL, C3>195mg/dL, C4>45 mg/dL, and MPV $>10.5 \mathrm{fL}$ were evaluated as increased; while C3 $<90 \mathrm{mg} / \mathrm{dL}, \mathrm{C} 4<10 \mathrm{mg} / \mathrm{dL}$, and MPV $<7.4 \mathrm{fL}$ were evaluated as decreased levels. In the literature, GIS and/or renal involvement in HSP patients were associated with decreased MPV, ${ }^{6}$ increased CRP, ${ }^{6-8}$ decreased complement ${ }^{9,10}$ and group A streptococcal infection. ${ }^{11}$ At the same time, the complement levels were found to increase in inflammatory pathologies. ${ }^{12}$ That's why decreased MPV, C3 and C4; increased CRP, $\mathrm{ASO}, \mathrm{C} 3$, and $\mathrm{C} 4$ were evaluated as risk factors. The clinical and laboratory findings predicting the organ or system involvement were tried to be determined.

Gastrointestinal (GI) involvement was defined as severe abdominal pain with or without GI bleeding determinants such as positive occult blood in stool, melena or hematochezia. Renal involvement was defined as the presence of hematuria ( $>5$ red blood cells per high-power microscopic field in a centrifuged specimen) with or without non-nephrotic proteinuria (in spot urine protein/creatinine ratio $>0.2$ or 4-40 $\mathrm{mg} / \mathrm{m}^{2} /$ per hour) or nephrotic syndrome (in spot urine protein/creatinine ratio $>2$ or $40 \mathrm{mg} / \mathrm{m}^{2} /$ per hour and serum albumin level less than $2.5 \mathrm{~g} / \mathrm{dL}$ with or without edema). Renal biopsy was performed in patients with persistent or nephrotic range proteinuria and in those with nephritic syndrome (hematuria, decreased glomerular filtration ratio, oliguria, hypertension, and edema). Renal biopsies were evaluated via light and immunofluorescence microscopy and graded according to the International Study of Kidney Disease in Children as follows: class I, minimal glomerular abnormalities; class II, pure mesangial proliferation (focal or diffuse); class III, crescents/segmental lesions $<50 \%$ (focal or diffuse); class IV, crescents/segmental lesions $50-75 \%$ (focal or diffuse); crescents/segmental lesions $>75 \%$ (focal or diffuse); class VI, pseudo mesangiocapillary changes. ${ }^{13}$

\section{Statistical analysis}

Statistical analysis was performed with IBM SPSS Statistical program version 22.0 (IBM Corp., Armonk, NY, USA). Continuous variables were compared with t-test and categorical variables were compared with chi-square test between the groups. Logistic regression analysis was performed to identify the prognostic effect of multiple variables. A $p$ value $\leq 0.05$ was considered statistically significant.

\section{RESULTS}

Male/female ratio of patients was 1.08. Thirty patients (16\%) were $>10$ years. Mean MPV value was $8.2 \pm 0.88 \mathrm{fL}$ (range, $5.7 \mathrm{fL}-11.1 \mathrm{fL}$ ). Decreased MPV levels were detected in 32 $(17.2 \%)$ and increased MPV levels were detected in three patients (1.6\%). Increased CRP and ASO were detected in $125(67.2 \%)$ and 66 patients (35.5\%), respectively. Serum IgA levels were evaluated in 167 patients and in 79 (47.3\%) of them, the levels were higher than the normal range. Complement components were measured in 172 patients. C3 and C4 levels were higher than normal in $41(23.8 \%)$ and 12 patients (7\%), 
Table 1. Laboratory parameters of patients

\begin{tabular}{lcc}
\hline Parameter & $\mathrm{n}$ & $\%$ \\
\hline Mean platelet volume $(<7.5 \mathrm{fL})$ & 32 & 17.2 \\
Mean platelet volume $(>10.5 \mathrm{fL})$ & 3 & 1.6 \\
C-reactive protein $(>0.5 \mathrm{mg} / \mathrm{dL})$ & 125 & 67.2 \\
Anti-streptolysin $(>200 \mathrm{IU} / \mathrm{mL})$ & 66 & 33.5 \\
Immunoglobulin $\mathrm{A}^{*}(>400 \mathrm{mg} / \mathrm{dL})$ & 79 & 47.3 \\
Complement component 3** (>195 mg/dL) & 41 & 23.8 \\
Complement component 4** $(>45 \mathrm{mg} / \mathrm{dL})$ & 12 & 7 \\
\hline * Serum immunoglobulin A levels were evaluated in 167 & patients; \\
** Complement components were measured in 172 patients. &
\end{tabular}

respectively. Decreased C3 and C4 levels were not observed in any patient. Laboratory findings were summarized in Table 1.

All patients had palpable purpura on the lower extremities while 60 patients $(32.3 \%)$ also had palpable purpura on the upper extremities. MPV, CRP, ASO, C3, and C4 levels were similar between the patients with or without purpura on the upper extremities ( $p>0.05)$. Testicular involvement was observed in 18 (18.5\%) of the boys. Fifty-five patients (29.6\%) had abdominal pain with or without GI bleeding and two of these patients had intussusception and were operated. Ninety-four patients (50.5\%) had arthritis or arthralgia mostly in the lower extremity joints. Only two patients (1\%) had arthritis in the upper extremities, one with and the other one without concurrent arthritis in the lower extremity. None of the patients with arthritis developed articular deformity. Eighty-one patients (43.5\%) had soft tissue swelling. Clinical findings were summarized in Table 2.

Twenty-eight patients (15.1\%) had renal involvement and 13 of them (6.9\%) had only hematuria, five (2.7\%) had proteinuria, and

\begin{tabular}{lcc}
\hline Table 2. Clinical characteristics of patients & & \\
\hline Clinical signs & $\mathrm{n}$ & $\%$ \\
\hline Purpura & 186 & 100 \\
$\quad$ Lower extremity & 186 & 100 \\
$\quad$ Lower + upper extremity & 60 & 32.3 \\
Joint involvement & 94 & 50.5 \\
$\quad$ (arthritis/arthralgia) & 81 & 43.5 \\
Soft tissue swelling & 55 & 29.5 \\
Gastrointestinal involvement & & \\
$\quad$ (abdominal pain with or without GI bleeding) & 28 & 15.1 \\
Renal involvement & 13 & 6.9 \\
$\quad$ Hematuria & 5 & 2.7 \\
$\quad$ Proteinuria & 10 & 5.4 \\
$\quad$ Hematuria + proteinuria & 18 & 18.5 \\
Testicular (boys) & & \\
\hline GI: Gastrointestinal. & & \\
&
\end{tabular}

10 (5.4\%) had both hematuria and proteinuria. Renal failure was not observed in any of the patients and none had nephritic syndrome. Only five patients (2.7\%) developed nephrotic syndrome and biopsy was performed in these patients. Three patients had class II (one focal finding and two diffuse findings), and two patients had class III (both focal findings) nephritis. All patients were treated with steroids and angiotensin converting enzyme inhibitors (ACEIs). Patients with class III nephritis also received pulse methylprednisolone (PMP) preceding oral steroids.

Logistic regression analysis revealed that the risk of GIS involvement was significantly higher in patients with skin lesions affecting the upper extremities $(p=0.002$, odds ratio $[O R]=3.2)$. The risk of joint involvement was significantly higher in girls $(p=0.024, O R=2.18)$, in patients with soft tissue edema $(p=0.005, O R=2.63)$, and lower MPV levels $(p=0.008, O R=4.07)$. The risk of renal involvement was significantly higher in girls

Table 3. Multifactorial analyses of covariances for effect of clinical and laboratory findings on organ/system involvement

\begin{tabular}{|c|c|c|c|c|c|}
\hline Organ/system involvement & Associated parameters & B & OR & $95 \% \mathrm{CI}$ & $p$ \\
\hline \multirow[t]{3}{*}{ Renal involvement } & Female sex & 0.922 & 2.7 & 1.014-7.175 & 0.047 \\
\hline & $>10$ years at admission & 0.338 & 1.4 & $1.190-1.653$ & 0.001 \\
\hline & High CRP levels & 1.884 & 6.57 & $1.679-25.782$ & 0.007 \\
\hline Gastrointestinal system involvement & Skin lesions with the upper extremities & 1.163 & 3.2 & $1.51-6.775$ & 0.002 \\
\hline \multirow[t]{2}{*}{ Skin lesions with the upper extremities } & GIS involvement & 1.322 & 3.75 & $1.782-7.899$ & 0.001 \\
\hline & Soft tissue involvement & 0.77 & 2.16 & $1.0542-4.424$ & 0.036 \\
\hline \multirow[t]{3}{*}{ Joint involvement } & Female sex & 0.778 & 2.18 & $1.110-4.272$ & 0.024 \\
\hline & Soft tissue involvement & 0.967 & 2.63 & 1.334-5.188 & 0.005 \\
\hline & Low MPV & 1.404 & 4.07 & $1.454-11.414$ & 0.008 \\
\hline Soft tissue involvement & Joint involvement & 0.864 & 2.37 & $1.216-4.628$ & 0.011 \\
\hline
\end{tabular}


$(p=0.047, O R=2.7)$, in patients $>10$ years of age $(p=0.001, O R=1.4)$, and in patients with elevated CRP levels $(p=0.007, O R=6.57)$. The risk of soft tissue involvement was significantly higher in patients with joint involvement $(p=0.011$, $\mathrm{OR}=2.37$ ). Testicular involvement or increased levels of IgA, ASO, C3, or C4 levels did not show any relationship with any of the variables. Logistic regression analysis findings were summarized in Table 3.

\section{DISCUSSION}

In this descriptive observational study, we retrospectively evaluated the profile and risk factors for different organ or system involvements in children with HSP. There are plenty of studies in the literature about the relationship between the laboratory and clinical findings and development of renal involvement in HSP. We also investigated the risk factors for GIS and joint involvement, in addition to renal involvement. Although most of our findings confirm previous observations, some of our results shed important insights into the complications and risk factors in children with HSP.

Henoch-Schönlein purpura can be diagnosed between the ages of 2 and 10 years. ${ }^{14}$ Although mostly seen in males, $, 910,15$ it has been shown to occur more frequently in females in a few studies. ${ }^{16}$ In our study, similar to the previous reports, the mean age of the 186 patients was $7.4 \pm 2.8$ years (range 1.5-16.5 years), and the number of boys and girls were almost the same with a boy to girl ratio of 1.08 .

Laboratory findings are not specific for the diagnosis of HSP. Increased serum IgA levels were found in 20-50\%, 7,17,18 increased complement levels were reported in 25\%,7 decreased complement levels were reported in 10-20\%, ${ }^{10,18}$ high ASO levels were reported in 33\%, ${ }^{9}$ and high CRP levels were reported in $27-71 \% \%^{7,19}$ of the patients. In our patients, levels of all abovementioned laboratory findings seem to be consistent with the literature but decreased complement levels were not observed in any of our patients. Increased IgA, ASO, C3 or C4 levels showed no relationship to any organ or system involvement.

The most common symptom of HSP is purpuric skin rash. Skin involvement was determined in $100 \%$ of our patients. All patients had palpable purpura on the lower extremities while 60 patients (32.3\%) had additional palpable purpura on the upper extremities, without any significant difference in laboratory findings.

The reported incidence of testicular manifestations ranges widely, from 2 to $38 \% .^{20-22}$ In our study, testicular involvement was observed in 18 boys (18.5\%), which was similar to the literature. We found that testicular involvement had no association with any other organ or system involvement.

Gastrointestinal involvement has been reported in 35 to $82 \%$ of the patients. ${ }^{15,23}$ The most common surgical complication in patients with GI involvement is intussusception and its incidence is less than $1 \% .^{6}$ In our study, GI involvement was found to be relatively less common compared to the literature. Fifty-five patients (29.6\%) had abdominal pain with or without GI bleeding and two of these patients were operated due to intussusception (1\%). It was suggested that low MPV levels might contribute to GI bleeding in HSP. ${ }^{6}$ Decreased MPV levels were detected in $32(17.2 \%)$ and increased MPV levels were detected in three (1.6\%) of our patients. We could not determine any relationship between GIS involvement and low MPV levels. We found that the risk of GIS involvement was 3.2 fold higher in patients with skin lesions on upper extremities. This association has not been denoted in the literature before.

Joint involvement is seen in about 60 to $84 \%$ of the patients..$^{9,15,23}$ In our study, joint involvement frequency was lower in comparison to the literature. Ninety-four patients (50.5\%) had arthritis/arthralgia mostly in the lower extremity joints. The risk of joint involvement was 2.18 fold higher in girls, and 2.63 fold increased in patients with soft tissue edema. Nevertheless, we found a nearly fourfold increased risk of joint involvement in patients with low MPV levels and also this association has not been denoted in the literature before. We have not been able to fully explain the cause of increased arthritis in patients with low MPV. MPV is known to be a marker determined from megakaryocytes during platelet production, which is associated with platelet function and activation. Under normal circumstances, there is an inverse relationship between platelet size and 
number. ${ }^{24,25}$ Recently, MPV has been considered a reliable marker for indicating platelet activation and inflammation. ${ }^{26}$ MPV has been studied as a simple inflammatory marker in several diseases. It decreases in active rheumatologic diseases including rheumatoid arthritis (RA), ankylosing spondylitis, ulcerative colitis, and systemic lupus erythematosus (SLE) ${ }^{27-29}$ This condition is thought to be related to the release of bioactive molecules of pro-inflammatory platelets in the presence of inflammation. ${ }^{29}$ It has been stated that high-grade inflammation accompanies a decrease of MPV in RA and SLE, possibly due to the increased consumption of large platelets at the sites of rheumatoid inflammation. ${ }^{26}$

Renal involvement is the most serious component of HSP, usually manifested as spontaneously resolving hematuria and/or proteinuria, or nephrotic syndrome, and it may rarely progress rapidly. In the literature, the frequency of HSP nephritis is about 15 to $62 \%$ but the incidence of renal failure is $0-3 \% .^{14,15,30}$ In our study, $15.1 \% \quad(n=28)$ of our patients had renal involvement with hematuria in 13, proteinuria in five, and hematuria and proteinuria in 10 patients. Nephritic or nephritic/nephrotic syndrome or renal failure was not observed in any of our patients. Renal involvement is usually reported to appear within the first three months. ${ }^{17}$ In our study, renal involvement was detected in 12 patients (44.4\%) at the time of diagnosis, in eight patients $(29.6 \%)$ in the first month, in four patients $(14.8 \%)$ between the first and the third months, and in three patients (11.1\%) between the fourth and the sixth months. Namely, in 88.9\% of the patients, renal involvement occurred in the first three months.

Biopsy was performed in five patients with nephrotic syndrome. Three patients had class II and two patients had class III nephritis. All patients received steroids and ACEIs. Patients with class III nephritis also received PMP. No further treatment was needed. In Kidney Disease Improving Global Outcomes (KDIGO) guideline, ACEIs alone are recommended for patients with class I-III nephritis. ${ }^{31}$ However, others suggested that this treatment option would be insufficient for suppressing the inflammation in cases with class III nephritis, namely those with crescents in the biopsy. ${ }^{32}$ In addition, it was found that the long-term prognosis was the worst in patients with nephrotic proteinuria. ${ }^{33,34}$ Thus, we preferred PMP in our cases with class III nephritis and used steroids in others with nephrotic syndrome.

In a recent meta-analysis, $>10$ years, male sex, white blood count $>15 \times 10^{\%} / \mathrm{L}$, platelets $>500 \times 10^{9} / \mathrm{L}$, elevated ASO, decreased C3, GIS involvement, persistent purpura, and relapse were found to be associated with renal involvement, while blood pressure, orchitis, elevated CRP, erythrocyte sedimentation rate or IgA levels showed no association. ${ }^{10}$ We also found that renal involvement is 1.4 fold increased in children $>10$ years of age. However, we found a 2.7 fold increased risk for renal involvement in girls, in contrast to previous studies. . $^{8,10,35,36}$ We found that renal involvement risk is 6.57 fold increased in patients with higher than normal CRP levels. Although some studies showed a positive correlation between CRP values and renal involvement,, 8 some others including the most recent meta-analysis found no correlation. ${ }^{10,35,37}$ We could not demonstrate any other association with other laboratory parameters in our study.

Although GIS involvement is mentioned as a risk factor for renal involvement in many previous studies, 7,8,10,17,30,35,37 we could not demonstrate any association. Purpura on sites other than the lower limbs ${ }^{33,35}$ and scrotal involvement ${ }^{7,9}$ were also described as risk factors, which we could not define. In the meta-analysis, scrotal involvement was not found to be associated with renal involvement, either. ${ }^{10}$

Our study has some limitations. The major limitations of this study are its retrospective design and inclusion of children who all attended the same clinic. In addition, we only evaluated laboratory values during the acute phase of the disease; hence, we might have missed the late onset changes. So, multicenter prospective studies including larger number of patients are needed to confirm and generalize our results.

In conclusion, our study did not demonstrate any relationship between GIS involvement and low MPV levels as mentioned before; however, skin lesions on upper extremities were found to increase the risk of GIS involvement. In addition, low MPV levels, female sex, and soft tissue edema were found to increase the risk for joint involvement. Only female sex, being 
$>10$ years of age, and high CRP levels were associated with renal involvement and most of our patients had renal problems within the first three months, particularly in the first month. We may conclude that the renal involvement in HSP is independent of GIS or joint involvement and very close follow-up is required in the acute period particularly in girls $>10$ years with high CRP levels.

\section{Acknowledgements}

For this retrospective study, we would like to thank The General Secretary of Public Hospitals Union for their permission to use the patient data of Gaziantep Children's Hospital.

\section{Declaration of conflicting interests}

The authors declared no conflicts of interest with respect to the authorship and/or publication of this article.

\section{Funding}

The authors received no financial support for the research and/or authorship of this article.

\section{REFERENCES}

1. Batu ED, Ozen S. Pediatric vasculitis. Curr Rheumatol Rep 2012;14:121-9.

2. Dereli N, Ozayar E, Degerli S, Sahin S, Bulus H. A rare complication of Henoch-Schönlein Syndrome: gastrointestinal infarction and perforation. Acta Gastroenterol Belg 2012;75:274-5.

3. Ozen S, Bakkaloglu A, Dusunsel R, Soylemezoglu O, Ozaltin F, Poyrazoglu $\mathrm{H}$, et al. Childhood vasculitides in Turkey: a nationwide survey. Clin Rheumatol 2007;26:196-200.

4. Cakar N, Ozçakar ZB, Soy D, Uçar Y, Fitöz S, Kara $\mathrm{N}$, et al. Renal involvement in childhood vasculitis. Nephron Clin Pract 2008;108:202-6.

5. Ozen S, Ruperto N, Dillon MJ, Bagga A, Barron K, Davin JC, et al. EULAR/PReS endorsed consensus criteria for the classification of childhood vasculitides. Ann Rheum Dis 2006;65:936-41.

6. Makay B, Türkyilmaz Z, Duman M, Unsal E. Mean platelet volume in Henoch-Schönlein purpura: relationship to gastrointestinal bleeding. Clin Rheumatol 2009;28:1225-8.

7. Wang X, Zhu Y, Gao L, Wei S, Zhen Y, Ma Q. Henoch-Schönlein purpura with joint involvement: Analysis of 71 cases. Pediatr Rheumatol Online J 2016;14:20.

8. Elmas AT, Tabel Y. Platelet Counts in Children With Henoch-Schonlein Purpura--Relationship to Renal
Involvement. J Clin Lab Anal 2016;30:71-4.

9. Tabel Y, Inanc FC, Dogan DG, Elmas AT. Clinical features of children with Henoch-Schonlein purpura: risk factors associated with renal involvement. Iran $\mathrm{J}$ Kidney Dis 2012;6:269-74.

10. Chan H, Tang YL, Lv XH, Zhang GF, Wang M, Yang HP, et al. Risk Factors Associated with Renal Involvement in Childhood HenochSchönlein Purpura: A Meta-Analysis. PLoS One 2016;11:0167346.

11. Schmitt R, Carlsson F, Mörgelin M, Tati R, Lindahl G, Karpman D. Tissue deposits of IgA-binding streptococcal M proteins in IgA nephropathy and Henoch-Schonlein purpura. Am J Pathol 2010;176:608-18.

12. Li W, Li H, Song W, Hu Y, Liu Y, DA R, et al. Differential diagnosis of systemic lupus erythematosus and rheumatoid arthritis with complements $\mathrm{C} 3$ and $\mathrm{C} 4$ and C-reactive protein. Exp Ther Med 2013;6:12711276.

13. Counahan R, Winterborn $\mathrm{MH}$, White RH, Heaton JM, Meadow SR, Bluett NH, et al. Prognosis of Henoch-Schönlein nephritis in children. Br Med J 1977;2:11-4.

14. Ozen S. The spectrum of vasculitis in children. Best Pract Res Clin Rheumatol 2002;16:411-25.

15. Peru H, Soylemezoglu O, Bakkaloglu SA, Elmas S, Bozkaya D, Elmaci AM, et al. Henoch Schonlein purpura in childhood: clinical analysis of 254 cases over a 3-year period. Clin Rheumatol 2008;27:1087-92.

16. Uppal SS, Hussain MA, Al-Raqum HA, Nampoory MR, Al-Saeid K, Al-Assousi A, et al. Henoch-Schönlein's purpura in adults versus children/adolescents: A comparative study. Clin Exp Rheumatol 2006;24(2 Suppl 41):S26-30.

17. Sano H, Izumida M, Shimizu H, Ogawa Y. Risk factors of renal involvement and significant proteinuria in Henoch-Schönlein purpura. Eur $J$ Pediatr 2002;161:196-201.

18. Trapani S, Micheli A, Grisolia F, Resti M, Chiappini E, Falcini $F$, et al. Henoch Schonlein purpura in childhood: epidemiological and clinical analysis of 150 cases over a 5-year period and review of literature. Semin Arthritis Rheum 2005;35:143-53.

19. Lardhi AA. Henoch-Schonlein purpura in children from the eastern province of Saudi Arabia. Saudi Med J 2012;33:973-8.

20. Dolezalová P, Telekesová P, Nemcová D, Hoza J. Incidence of vasculitis in children in the Czech Republic: 2-year prospective epidemiology survey. J Rheumatol 2004;31:2295-9.

21. Ha TS, Lee JS. Scrotal involvement in childhood Henoch-Schönlein purpura. Acta Paediatr 2007;96:552-5.

22. Hara Y, Tajiri T, Matsuura K, Hasegawa A. Acute scrotum caused by Henoch-Schönlein purpura. Int $\mathrm{J}$ Urol 2004;11:578-80. 
23. Mir S, Yavascan O, Mutlubas F, Yeniay B, Sonmez F. Clinical outcome in children with Henoch-Schönlein nephritis. Pediatr Nephrol 2007;22:64-70.

24. Jackson SR, Carter JM. Platelet volume: laboratory measurement and clinical application. Blood Rev 1993;7:104-13.

25. Threatte GA. Usefulness of the mean platelet volume. Clin Lab Med 1993;13:937-50.

26. Gasparyan AY, Ayvazyan L, Mikhailidis DP, Kitas GD. Mean platelet volume: a link between thrombosis and inflammation? Curr Pharm Des 2011;17:47-58.

27. Yüksel O, Helvaci K, Başar O, Köklü S, Caner S, Helvaci N, et al. An overlooked indicator of disease activity in ulcerative colitis: mean platelet volume. Platelets 2009;20:277-81.

28. Kisacik B, Tufan A, Kalyoncu U, Karadag O, Akdogan A, Ozturk MA, et al. Mean platelet volume (MPV) as an inflammatory marker in ankylosing spondylitis and rheumatoid arthritis. Joint Bone Spine 2008;75:291-4.

29. Safak S, Uslu AU, Serdal K, Turker T, Soner S, Lutfi A. Association between mean platelet volume levels and inflammation in SLE patients presented with arthritis. Afr Health Sci 2014;14:919-24.

30. Lee YH, Kim YB, Koo JW, Chung JY. Henoch-Schonlein Purpura in Children Hospitalized at a Tertiary Hospital during 2004-2015 in Korea: Epidemiology and Clinical Management. Pediatr
Gastroenterol Hepatol Nutr 2016;19:175-185.

31. Kidney Disease Improving Global Outcomes (KDIGO) guidelines on glomerulonephritis. HenochSchönlein purpura nephritis. Kidney Int Suppl 2012;2:218-20.

32. Davin JC, Coppo R. Pitfalls in recommending evidence-based guidelines for a protean disease like Henoch-Schönlein purpura nephritis. Pediatr Nephrol 2013;28:1897-903.

33. Ronkainen J, Ala-Houhala M, Huttunen NP, Jahnukainen T, Koskimies O, Ormälä T, et al. Outcome of Henoch-Schoenlein nephritis with nephrotic-range proteinuria. Clin Nephrol 2003;60:80-4.

34. Davin JC, Coppo R. Henoch-Schönlein purpura nephritis in children. Nat Rev Nephrol 2014;10:56373.

35. Mao Y, Yin L, Huang H, Zhou Z, Chen T, Zhou W. Henoch-Schönlein purpura in 535 Chinese children: clinical features and risk factors for renal involvement. J Int Med Res 2014;42:1043-9.

36. Ozturk K, Ekinci Z. Is neutrophil-to-lymphocyte ratio valid to predict organ involvement in HenochSchönlein purpura? Rheumatol Int 2016;36:1147-8.

37. Jauhola O, Ronkainen J, Koskimies O, Ala-Houhala M, Arikoski P, Hölttä T, et al. Renal manifestations of Henoch-Schonlein purpura in a 6-month prospective study of 223 children. Arch Dis Child 2010;95:877-82. 